\title{
EMPOASCAN LEAFHOPPERS OF THE SOLANA GROUP WITH DESCRIPTIONS OF TWO NEW SPECIES
}

\author{
(HOMOPTERA, CICADELLIDAE)
}

\author{
David A. Young, Jr. ${ }^{1}$
}

\section{INTRODUCTION}

Recently, in attempting to identify a species of Empoasca collected from papaya, the writer had great difficulty in establishing the identity of Empoasca dilitara DeLong and Davidson, to which the papaya-feeding species had previously been referred. A later examination of the type of $E$. dilitara eliminated"it as a possibility, but its similarity to the unknown species and to others previously examined; led to a study of this group of similar forms which heretofore have not been associated in the literature dealing with the genus Empoasca. The group is here designated the solana group.

The males of the solana group are characterized by the simple rounded anal hooks, the presence of large ventral abdominal apodemes (presumably present in manda of which only the apex of the abdomen was studied), styles that are usually concavely truncate apically and with distinct preapical teeth, and the form of the processes of the ninth segment (pygofer processes) which tend to be elongate, constricted anteapically, and with the apices abruptly narrower than the broader basal portion. All the species possess aedeagal processes. The group is primarily tropical and subtropical in the Western Hemisphere, and at least one species is common in temperate North America.

The possibility of subspeciation in this group of closely related forms has not been ignored, but in view of the incomplete knowledge of distribution and in the light of the breeding experiments with species of this genus by F. W. Poos and his coworkers, it appears advisable to treat the forms as species at this time.

Species included in the key but not described here are being treated in another publication. All the species known to fall within this group, as characterized above, are included in the key.

The terminology employed in the descriptions of the male genitalia is explained in a recent work on Typhlocybinae (1). ${ }^{2}$

Examination of the types of several of the species included in this study

${ }^{1}$ Bureau of Entomology and Plant Quarantine, Agricultural Research Administration, U. S. Department of Agriculture, Washington, D.C.

${ }^{2}$ Numbers in parentheses refer to Literature Cited, p. 160. 
was made possible through the kindness of D. M. DeLong of Ohio State University.

\section{KEY TO SPECIES}

1. Aedeagal processes (or the more conspicuous pair if two pairs are present), in lateral aspect with apices extending to a point less than half the length of caudal margin of aedeagal shaft.........2 Aedeagal processes, in lateral aspect with apices extending to a point more than half the length of caudal margin of shaft......6

2. All aedeagal processes minute, in lateral aspect superimposed on shaft throughout their length (fig. I, $1 \mathrm{~b}^{3}$ ). . canavalia, DeLong. One pair of aedeagal processes conspicuous in lateral aspect, not superimposed on the shaft at any point in their length..........

3. Aedeagal shaft with dorsal extremity strongly procurved, broad, and distinctly truncate (fig. I, $2 \mathrm{~b}$ )........... stevensi $\mathrm{n}$. sp. Aedeagal shaft with dorsal extremity not or very weakly procurved, acute or rounded, not truncate.................. 4

4. Aedeagal shaft, in lateral aspect with caudal margin elongaterectilinear (fig. I, 3b)..................... solana DeLong. Aedeagal shaft in lateral aspect with caudal margin broadly

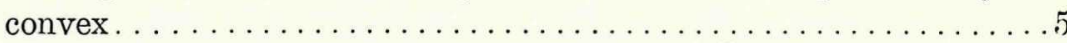

5. Pygofer processes in broadest aspect very broadly expanded anteapically, abruptly narrowed near apex; aedeagus with two pairs of processes, one pair very inconspicuous and superimposed on shaft in lateral aspect (fig. I, 4)

manda Davidson and DeLong. Pygofer processes much more gradually narrowed near apex; aedeagus with a single pair of processes (fig. I, 5)

dilitara DeLong and Davidson.

6. Aedeagal shaft, in lateral aspect, narrowest near midlength, distinctly broader basally and apically (fig. II, $6 \mathrm{~b}$ )

plebeia DeLong and Davidson. Aedeagal shaft with least width at its apex..............

7. Aedeagal shaft with apic al portion curved through 90 degrees.....8 Aedeagal shaft much less strongly curved in apical portion.......11

8. Aedeagus with base of preatrium elbowed, with a single pair of conspicuous processes. . . . . . . . . . . . . . . .

${ }^{3}$ Since it would have involved considerable delay to have the illustrations relettered, they are being used as lettered by the author, though not in Journal style. 


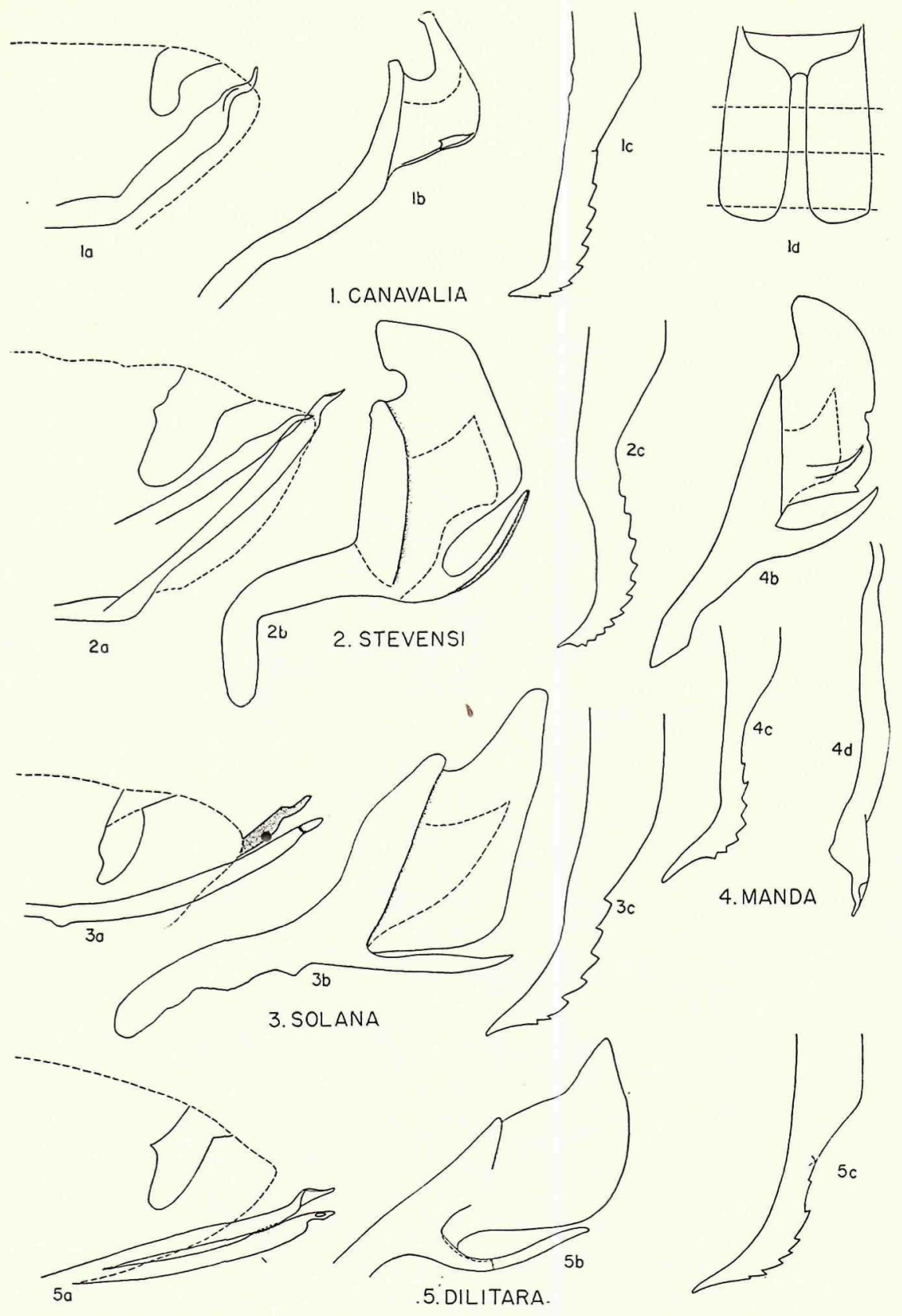

FIG. I.-In all of the species illustrated, " $a$ " is the pygofer in lateral aspect showing one anal hook and one pygofer process (unless two are shown); " $b$ " is the aedeagus in lateral aspect; and "c" is a style apex. 1, Empoasca canavalia: d, Sternal abdominal apodemes, with broken lines representing abdominal conjunctivae. All drawings from holotype. 2, E. stevensi: a, From paratype, both pygofer processes shown; b and c from holotype. 3, E. solana: a, Both pygofer processes shown; b and c observed through wall of genital chamber. All drawings from holotype. 4, E. manda: d, Right pygofer process, ventral aspect. All drawings from holotype. $5, E$. dilitara: a, Both pygofer processes shown; $\mathrm{b}$, one aedeagal process broken; $\mathrm{c}$, observed through wall of genital chamber. All drawings from holotype. 

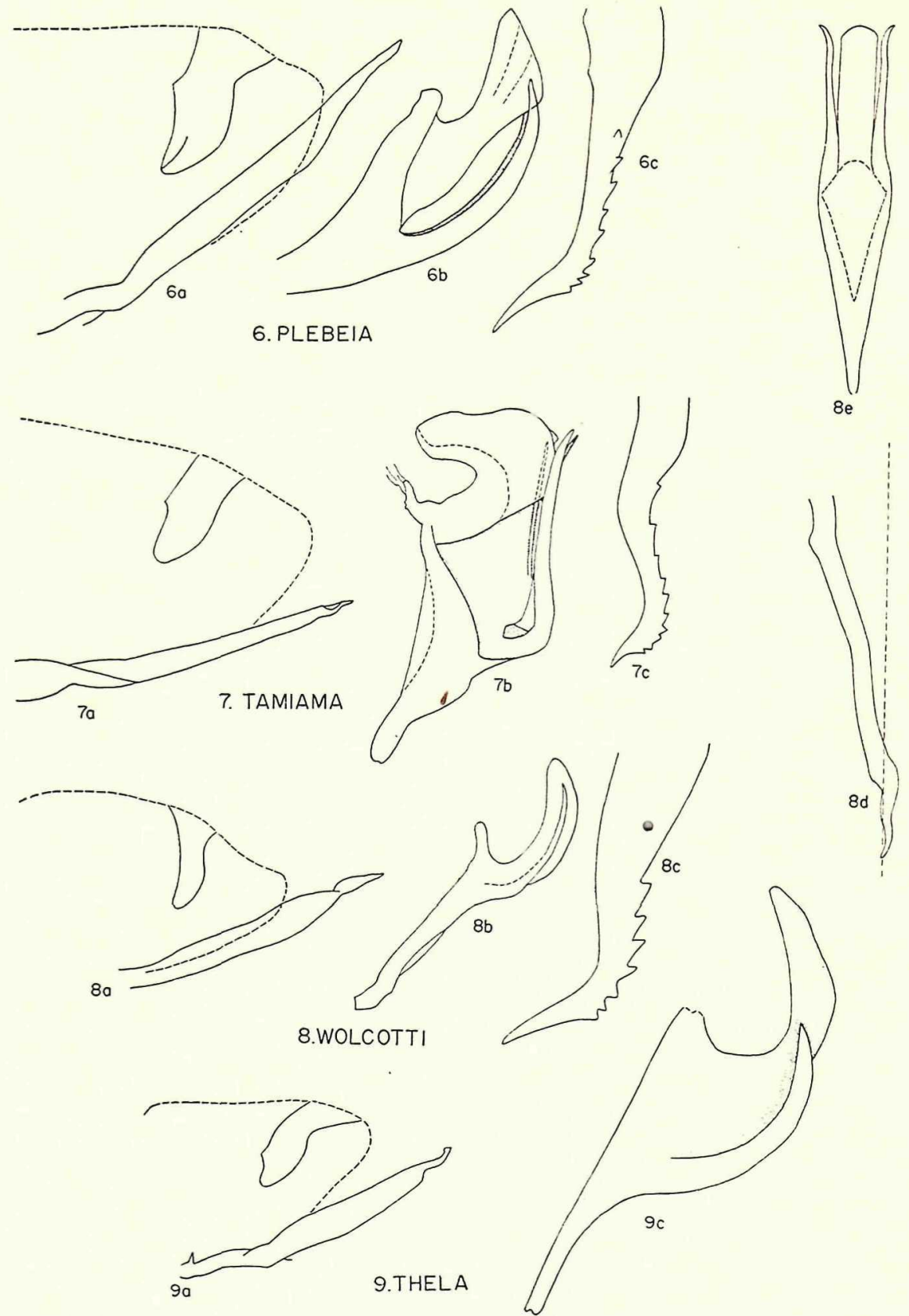

FIG. II.-In all of the species illustrated, " $a$ " is the pygofer in lateral aspect showing one anal hook and one pygofer process; " $\mathrm{b}$ " is the aedeagus in lateral aspect; and "c" is a style apex. 6, Empoasca plebeia: All drawings from holotype. 7, E. tamiama: $\mathrm{b}$ and $\mathrm{c}$ Observed through wall of genital chamber. All drawings from paratype. 8, E. wolcotti: d, Pygofer process in ventral aspect (broken line represents midventral line of specimen); e, aedeagus in caudal aspect. Drawing a from holotype b-e from paratype. $9, E$. thela: Both illustrations from homoeotype. 
Aedeagus with preatrium straight, with a pair of large conspicuous processes and pair of small extremely slender processes (fig. II, 7b) tamiama Davidson and DeLong.

9. Aedeagal process in lateral aspect attaining apex of shaft caldwelli Davidson and DeLong Aedeagal processes in lateral aspect with apices much basad of apex of shaft. . . . . . . . . . . . . . . . . . . . . 10

10. Aedeagal processes asymmetrical, apex of style oblique

Aedeagal processes symmetrical, apex of style transverse

$$
\text { hyalina (Osborn) }
$$

olivatula Osborn

11. Pygofer processes appearing twisted apically; aedeagal processes in caudal aspect not greatly divergent from shaft (fig. II, 8)

wolcotti n. sp.

Pygofer processes not appearing twisted apically; aedeagal processes in caudal aspect greatly divergent from shaft (fig. II, 9) thela Davidson and DeLong.

\section{Empoasca canavalia DeLong}

(Fig. I, 1)

This species was described from Damien, Haiti $(2,114)$.

Without diagnostic, external specific characters. Pygofer processes convergent in ventral aspect, appearing jointed anteapically as result of abrupt dorsal curvature, apices sharp and strongly convergent but not contiguous; in lateral aspect, processes slightly exceeding posterodorsal pygofer margin, each process elbowed at base, of fairly uniform width to slightly broader apical portion, apical portion bisinuate and gradually narrowed, the extreme tip acute and directed dorsad. Aedeagus with preatrium greatly elongate and gradually curved posterodorsad; atrial border strong; shaft short, laterally compressed, curved through 90 degrees, with pair of short, acute, inconspicuous appressed lateral processes, these appearing superimposed on shaft in lateral aspect.

Holotype male in collection of D. M. DeLong. Above description based on holotype.

\section{Empoasca stevensi n. sp.}

(Fig. I, 2)

A yellowish-green species, closely related to dititara DeLong and Davidson, but without external diagnostic specific characters. Length of male approximately $2.8 \mathrm{~mm}$., of female approximately $2.9 \mathrm{~mm}$.

Style apex and anal hook as described for the species group. Pygofer processes as in dilitara. Aedeagus laterally compressed; preatrium well- 
developed, distinctly elbowed; atrial border strong; shaft curved through 90 degrees in apical half, the apex procurved and truncate, caudal margin rectilinear; a pair of ventral atrial processes extending beneath base of shaft, nowhere superimposed on shaft in lateral aspect; in ventral aspect, the aedeagal processes very slightly divergent apically.

Holotype male, allotype female, taken on papaya in Orlando, Fla., March 1940, by H. E. Stevens for whom the species is named (U. S. N. M. Cat. No. 61596) and 12 paratypes, same data, in U. S. National Museum collection.

\section{Empoasca solana DeLong}

(Fig. I, 3)

Originally described from Louisiana (3, p. 50).

Without diagnostic external specific characters. Pygofer processes convergent posteriorly, crossing midventral line or not, elongate, exceeding apex of pygofer, each gradually tapering from near midlength distad, abruptly narrower and arcuate at apex; in one aspect apex very similar to that illustrated for thela Davidson and DeLong. Aedeagus laterally compressed; preatrium well-developed; atrial border strong, giving off a pair of ventral appressed processes which, in lateral aspect, are gradually tapered in their apical halves to acute apices, and nowhere superimposed on aedeagal shaft; shaft extremely broad with a prominent dorsal apical lobe which is not procurved; caudal margin elongate, subrectilinear.

This species appears to have a wide neotropical distribution and extends well into temperate North America. The holotype male, from Baton Rouge, is in the U. S. National Museum collection. The above description is based on the holotype.

The irregular ventral margin of the aedeagal preatrium which occurs in the holotype, apparently represents an individual variation, and was not present in any of a number of other specimens examined.

\section{Empoasca manda Davidson and DeLong}

(Fig. I, 4)

Originally described from Florida $(4$, p. 111).

Closely related to tamiama Davidson and DeLong in structure of male genitalia. Without diagnostic external specific characters. Pygofer processes in broadest (near-ventral) aspect gradually widened from base to near apex, greatly widened anteapically, thence abruptly narrowed on outer margin to slender apical process which is differentially sclerotized in such a manner that the more heavily sclerotized portion is extremely slender and undulate. Aedeagus laterally compressed; preatrium well-developed, almost straight, very slightly curved at base; atrial border strong; in lateral aspect a pair of processes arising near apex of preatrium and ex- 
tending in a smooth curve posterodorsad, gradually narrowed from their bases to apices, apices not attaining midlength of posterior margin of aedeagal shaft; in caudal aspect these processes appressed basally, slightly divergent apically; shaft very broad, extending dorsad, the apex slightly procurved, the posterior margin broadly convex (erose in dissected holotype), with a pair of very inconspicuous shaft processes arising near base and extending posterodorsad in a smooth curve, these processes appressed to shaft and indistinct in caudal aspect.

The male holotype, Dade County, Fla., is in the DeLong collection. Because the holotype had been dissected before examination by the writer, the pygofer processes and anal hook were not illustrated in situ. The sternal apodemes were not included in the preparation of the holotype. Judging from the appearance of the posterior margin of the aedeagal shaft, the erose condition of the holotype is probably not general in this species. As is commonly the case in Empoasca species, the dissected male genitalia offer sufficient characters for ready identification, and the lack of an illustration of the genital capsule with the parts in situ probably will not be a handicap.

\section{Empoasca dilitara DeLong and Davidson}

(Fig. I, 5)

This species was described from Eddy County, N. Mex. (5, p. 36).

Without diagnostį external specific characters. Pygofer processes convergent posteriorly, crossed apically, in lateral aspect, each process abruptly narrowed apically by preapical convergence of ventral margin, with extreme tip obliquely truncate and with an apparent anteapical minute areolet; in ventral aspect, processes gradually widened on apical halves, each with outer margin convergent to inner margin to form acute tip. Aedeagus laterally compressed; preatrium well-developed, straight; atrial border weak; shaft broad in lateral aspect, directed dorsad, scarcely procurved apically, caudal margin broadly convex; with a pair of slender short atrial processes extending dorsad for less than half length of shaft, slightly divergent posteriorly in ventral aspect; in lateral aspect nowhere superimposed on shaft.

The holotype male is in the collection of D. M. DeLong. The above description is based on the holotype.

\section{Empoasca plebeia DeLong and Davidson}

(Fig. II, 6)

This species was originally described from Belle Glade, Fla. (5, p. 34).

Without diagnostic external specific characters. Pygofer processes gradually convergent throughout their length, their extreme tips approximate 
or contiguous; in lateral aspect, processes very long, exceeding apex of pygofer, each process gradually expanded on ventral margin beyond midlength, ventral margin thence gradually and somewhat irregularly convergent to dorsal margin, the apex not abruptly narrowed. Aedeagus laterally compressed; preatrium well-developed, straight; atrial border strong, in lateral aspect a pair of processes arising just ventrad of base of shaft, these elongate, arcuate, superimposed on shaft only at their apices which intersect ventral shaft margin but fail to attain caudal shaft margin; shaft not arcuate, directed posterodorsad, conspicuously narrower at midlength than at base or apex; in caudal aspect, aedeagal processes approximate and subparallel almost to their apices which are gradually divergent.

The holotype male, is in the collection of D. M. DeLong. The above description is based on the holotype.

\section{Empoasca tamiama Davidson and DeLong}

(Fig. II, 7)

This species was described originally from the Tamiami Trail, Fla. (4, p. 117), and redescribed as Empoasca eweraformis (6, p. 121) by Caldwell (new synonymy).

Without diagnostic external specific characters. Pygofer processes slightly convergent posteriorly in ventral aspect, but not crossing midventral line; in lateral aspect each process gradually tapered to preapical portion, short apical portion much narrower, its ventral margin broadly convex, the adjacent dorsal margin presenting the appearance of a small areolet, the extreme tip acute; in ventral aspect each process strongly concave at apex. Aedeagus laterally compressed; preatrium extremely short; atrial border strong; shaft curved through 90 degrees in apical half, giving off one pair of conspicuous appressed processes fused at their bases, extending along caudal margin of shaft through apical portions of their lengths, and a second pair of inconspicuous elongate slender straight processes near midlength, these not attaining dorsal margin of shaft, and with their apical halves apparently overlaid by an oblique hoodlike expansion of the dorsal portion of the shaft.

The male holotype is presumably in the collection of D. M. DeLong. The above description is based on a male paratype.

The holotype of eweraformis Caldwell has been studied. The new synonoymy extends the range of tamiama to Puerto Rico. Previously it has been reported only from Florida.

Empoasca wolcotti n. sp.

(Fig. II, 8)

A yellowish species with a well-produced head, but without diagnostic external specific characters. Pygofer processes gradually approximate 
throughout their lengths, their apical portions narrower, bisinuate, and crossed or superimposed in ventral aspect; in lateral aspect, processes elongate, each considerably exceeding apex of pygofer, broader on basal portion, appearing somewhat constricted and twisted anteapically, the portion distad of the constriction gradually tapered. Aedeagus laterally compressed; preatrium elongate, slightly elbowed basally, the posterior face concave; shaft smoothly curved, of uniform width throughout most its length, the apex smoothly rounded and directed cephalad; with a pair of processes arising at or near the atrial border, and extending distad in a curve nearly approximating curvature of shaft, not attaining apex of shaft, superimposed on shaft in lateral aspect, slightly divergent from shaft in caudal aspect. Style apex and anal hook characteristic of the species group.

Holotype male, allotype female, and a long series of paratypes of both sexes, Corozal, Puerto Rico, March 17, 1951 and March 20, 1951, collected "on wild pumpkin" by Julio Bird (U. S. N. M. Cat. No. 61597), in United States National Museum collection.

In addition to the above series, one specimen has been examined which was collected from cotton on March 29, 1952, also by Bird. This species is dedicated to G. N. Wolcott, whose persevering work has contributed greatly to our knowledge of Puerto Rican Homoptera.

\section{Empoasca thela Davidson and DeLong}

\section{- (Fig. II, 9)}

This species was described originally (4, p. 113) from Brownsville, Texas.

Without diagnostic external specific characters. Pygofer processes not crossing midventral line, in ventral aspect each process gradually tapered, the short apical portion arched and the pair of arches parentheseslike in form; in lateral aspect, each process elongate, considerably exceeding apex of pygofer, gradually broadened from base to midlength, thence gradually narrowed to apex which is abruptly narrowed by convergence of ventral margin, upcurved, and truncate at extreme tip. Aedeagus laterally compressed; preatrium short, shaft smoothly but strongly curved dorsad, much narrower than in solana, with a pair of arched ventral processes arising near base, appearing superimposed on shaft throughout their length in lateral aspect, their apices acute; in caudal aspect, aedeagal processes greatly divergent from shaft; shaft slightly narrowed at midlength, but not conspicuously constricted as in plebeia.

The male holotype presumably is in the collection of D. M. DeLong. The above description is based on a male homoeotype.

\section{SUMMARY}

Difficulty in establishing the identity of a species of Empoasca collected on papaya led to a study of a primarily neotropical group of species related 
to Empoasca solana. The group includes canavalia, solana, manda, dilitara, plebeia, tamiama, caldwelli, hyalina, olivatula, thela, and two new species: stevensi and wolcotti. A key to the 12 species, and descriptions of 9 of them are included.

\section{RESUMEN}

La dificultad existente para identificar una especie de Empoasca, colectada en el árbol de papaya, motivó un estudio sobre un grupo neotropical de especies afines a la Empoasca solana. El grupo incluye las especies canavalia, solana, manda, dilitara, plebeia, tamiama, caldwelli, hyalina, olivatula, thela, y dos nuevas especies: stevensi y wolcotti. Se incluye una clave para identificar 12 especies y se describen 9 de éllas.

\section{LITERATURE CITED}

1. Young, D. A., A reclassification of Western Hemisphere Typhlocybinae, Univ. Kans. Sci. Bull. 35 1-217, 1952.

2. DeLong, D. M., Three species of Empoasca leafhoppers known to affect economic plants in Haiti, J. Dept. Agr. P. R. 16 113-15, 1932.

3. DeLong, D. M., A revision of the American species of Empoasca known to occur North of Mexico, U. S. D. A. Tech. Bul. 231 1-59, 1933.

4. Davidson, R. H. and DeLong, D. M., Studies of the genus Empoasca, Pt. VI, Ohio J. Sci. 39 110-18, 1939.

5. DeLong, D. M. and Davidson, R. H., Further studies of the genus Empoasca, Pt. III, Ohio J. Sci. 36 29-39, 1935.

6. Caldwell, J. S. and Martorell, L. F., Review of the auchenorynchous Homoptera of Puerto Rico, Pt. I, Cicadellidae, J. Agr. Univ. P. R. 34 1-132, 1952. 